\title{
$n$-3 Oil sources for use in aquaculture - alternatives to the unsustainable harvest of wild fish
}

\author{
Matthew R. Miller ${ }^{1,2 *}$, Peter D. Nichols ${ }^{1}$ and Chris G. Carter ${ }^{3}$ \\ ${ }^{1}$ CSIRO Food Futures Flagship and Division of Marine and Atmospheric Research, GPO Box 1538, Hobart, Tasmania 7001, \\ Australia \\ ${ }^{2}$ Crop \& Food Research, Processed Foods Group, PO Box 5114, Nelson, New Zealand 7000, New Zealand \\ ${ }^{3}$ National Centre for Marine Conservation and Resource Sustainability, Locked Bag 1370, Launceston, Tasmania 7250, \\ Australia
}

\begin{abstract}
The present review examines renewable sources of oils with $n$-3 long-chain $\left(\geq \mathrm{C}_{20}\right)$ PUFA (n-3 LC-PUFA) as alternatives to oil from wild-caught fish in aquafeeds. Due to the increased demand for and price of wild-caught marine sources of $n$-3 LC-PUFA-rich oil, their effective and sustainable replacement in aquafeeds is an industry priority, especially because dietary $n-3$ LCPUFA from eating fish are known to have health benefits in human beings. The benefits and challenges involved in changing dietary oil in aquaculture are highlighted and four major potential sources of $n-3$ LC-PUFA for aquafeeds, other than fish oil, are compared. These sources of oil, which contain $n$-3 LC-PUFA, specifically EPA $(20: 5 n-3)$ and DHA $(22: 6 n-3)$ or precursors to these key essential fatty acids, are: (1) other marine sources of oil; (2) vegetable oils that contain biosynthetic precursors, such as stearidonic acid, which may be used by fish to produce $n$-3 LC-PUFA; (3) single-cell oil sources of $n$-3 LC-PUFA; (4) vegetable oils derived from oil-seed crops that have undergone genetic modification to contain $n-3$ LC-PUFA. The review focuses on Atlantic salmon (Salmo salar L.), because it is the main intensively cultured finfish species and it both uses and stores large amounts of oil, in particular $n-3$ LCPUFA, in the flesh.
\end{abstract}

\section{Long-chain PUFA: Aquaculture: Fish oil: Vegetable oil: Atlantic salmon: Phytosterols}

\section{Introduction}

\section{Sustainability of wild fish stocks}

Historically, the intensive culture of Atlantic salmon (Salmo salar L.) has relied on natural fisheries to supply fishmeal and oil as ingredients for aquafeeds. Therefore the stability and sustainability of the wild fishery are of vital importance to the security of ingredients for aquafeeds. Worldwide, capture fisheries have plateaued at about 85-95 million tonnes per annum even though fishing effort has intensified $^{(1,2)}$. However, there is a growing concern about the health of global fisheries stocks and the ecological effects of industrial fishing, with evidence that many fisheries are fully or over-fished ${ }^{(1,3-6)}$. Fish oil and meal production is strongly dependent on the availability of wild fisheries and the mismatch between demand and expected supply of fish oil is expected to reach 40 million tonnes by $2030^{(7)}$. Dramatic decreases, even collapse, can occur in fish populations of the species involved in fish oil production $^{(1,8)}$. Problems facing most fisheries are complex and stock decreases can be caused by numerous environmental, biological and ecological factors, not necessarily fishing impacts ${ }^{(8)}$. For instance, climatic events such as El Niño can significantly decrease fish populations and therefore increase pressure on fish oil and meal supply $^{(9-11)}$. One-quarter of the world's fish oil supply and one-third of the fish meal for aquaculture diets come from one anchoveta (Engraulis ringens) fishery off the coast of Peru $^{(8,12)}$. Collapse of this fishery alone would increase the pressure on world fish meal and oil supply and threaten the security of global aquaculture production ${ }^{(8,12)}$.

\section{Sustainable Atlantic salmon farming}

Aquaculture is the fastest growing food-producing sector in the world ${ }^{(7)}$. Atlantic salmon aquaculture production has grown from 55000 tonnes in 1985 to more than 1.2 million tonnes in $2006^{(13,14)}$. By 2010 it is estimated that $85 \%$ of

Abbreviations: ALA, $\alpha$-linolenic acid; LC, long-chain $\left(\geq \mathrm{C}_{20}\right)$; PCB, polychlorinated biphenyls; SDA, stearidonic acid.

* Corresponding author: Dr Matthew Miller, fax + 633546 7049, email MillerM@crop.cri.nz 
global fish oil will be needed for salmon and trout production $^{(15)}$. However, fish oils are increasingly being used in the nutraceutical and agricultural industries, and thus both demand and price have substantially increased, stimulating the need for replacement oils. Replacement of fish oil with renewable land-based products such as vegetable oils has been extensively researched and the results incorporated into currently used commercial aquafeeds $^{(16-19)}$.

The present review evaluates how an ecologically sustainable salmon aquaculture industry might be achieved via use of secure and sustainable $n$-3 long-chain $\left(\geq \mathrm{C}_{20}\right)$ (LC)-PUFA oil options that are not based on wild fish catch. The review is also relevant to the sustainable culture of other fish species.

\section{Discussion}

Salmon are carnivorous and require dietary protein and lipid that have traditionally been supplied from wild-caught marine sources. Feed efficiency for Atlantic salmon aquaculture is continually improving through the use of highly specified aquafeeds; currently about $1 \mathrm{~kg}$ of fish is produced per $\mathrm{kg}$ of feed. Although an estimated $3.2 \mathrm{~kg}$ of wild fish stock is required to produce $1 \mathrm{~kg}$ of aquafeed for salmon aquaculture ${ }^{(1,2)}$, aquaculture has a significant ecological advantage over wild salmon capture since $1 \mathrm{~kg}$ of growth in the wild equates to $10-15 \mathrm{~kg}$ of fish eaten by carnivorous fish or captured as by-catch ${ }^{(20,21)}$. The efficiency of the aquaculture industry is also continually improving as nutritional requirements are better understood. However, further research into sustainability and security of feed ingredients is vital for the growth of the industry.

\section{Lipid content and nutrition of aquafeeds}

Lipids provide the main source of metabolic energy in aquafeeds for many carnivorous fish, particularly salmonids. Current extrusion technologies allow aquafeeds to contain up to $40 \%$ oil. The natural marine diet of Atlantic salmon contains high concentrations of $n$-3 LC-PUFA, in particular EPA and DHA, low concentrations of $n-6$ PUFA, and moderate amounts of MUFA and SFA (Table 1).

The lipid component of aquafeeds requires the inclusion of $n-3$ and $n-6$ essential fatty acids which are necessary for cellular metabolism (synthesis of prostaglandins, eicosanoids, leucotrienes and other essential fatty acid metabolites) and for maintaining cell membrane structure and integrity ${ }^{(22,23)}$. Digestion, absorption, transport, accumulation, biosynthesis and metabolism of lipids, in particular essential fatty acids and $n-3$ LC-PUFA, have been studied in Atlantic salmon and reviewed elsewhere ${ }^{(22,24-27)}$.

Atlantic salmon can show nutritional 'diseases' or pathologies due to lipid imbalances ${ }^{(28-30)}$. They can display reduced growth, poor feed efficiency, evacuolated pyloric caeca tissue and increased incidence of pancreatic disease with essential fatty acid-deficient $\operatorname{diets}^{(28)}$. It is therefore a requirement that aquafeeds supply $n-3$ LC-PUFA as a part of the oil component if it is not supplied by residue oil in the fish meal ${ }^{(22)}$. It has been demonstrated that a diet consisting of $100 \%$ vegetable oil and therefore lacking $n$-3 LC-PUFA causes severe heart lesions, thinning of ventricular walls, muscle necrosis and can influence the devolvement of arteriosclerotic changes in Atlantic salmon ${ }^{(29,30)}$.

Currently, $n$-3 LC-PUFA for aquafeeds are mainly sourced from marine oil obtained from wild fisheries. Over the past 10 years, the intensive aquaculture industry has been using fish oil blended with vegetable and animal oil in the manufacture of aquafeeds to reduce cost and, to a lesser extent, to decrease the pressure on this finite resource. Many trials with replacement oils have demonstrated that the fatty-acid profile of the salmon closely reflects that of its $\operatorname{diet}^{(13,16,31-42)}$. It is suggested that in Atlantic salmon, $75 \%$ of dietary fish oil can be replaced by vegetable oil without compromising growth and performance or significantly affecting fish health or welfare if $n-3$ LC-PUFA requirements are met ${ }^{(19,35,43)}$. Vegetable oils do not contain any $n-3$ LC-PUFA, but can contain higher concentrations of SFA (in the case of palm oil), MUFA and $n-6$ PUFA $^{(44)}$. Salmon fed replacement vegetable oils have a reduced $n-3$ LC-PUFA content, which is a reflection of these diets.

It is important to monitor any potential aquafeed oil source for xenobiotics such as dioxins and dioxin-like polychlorinated biphenyls (PCB). Recently, there has been increased interest in the quality and toxicological properties of fish oil as an ingredient in aquafeeds for salmon aquaculture ${ }^{(45-50)}$. There are considerable health concerns associated with the presence of dioxins and dioxin-like PCB residues in fish oil ${ }^{(45,46)}$. Concentrations of such residues vary greatly in fish oil sources from around the world with seasonal and/or spatial variations common ${ }^{(45)}$. Dioxins and PCB are fat-soluble xenobiotics that are carcinogenic to humans $^{(47,51)}$ and are also known to cause skin ailments, liver disease, reproductive disorders and neurological problems ${ }^{(52)}$. Furthermore, dioxins and PCB are lipophilic and resistant to degradation, and therefore can accumulate in significant concentrations in fish oil. Lastly, dioxins and PCB can persist in the environment for many years and they bioaccumulate up the food chain, with potential harmful effects for the human consumer. Alternative oils such as vegetable or single-cell oils have a very minor possibility of containing dioxins and PCB, making them favourable as replacement oils in aquafeeds ${ }^{(53)}$.

\section{n-3 and n-6 PUFA}

Recently, it has been generally acknowledged that when incorporating alternative lipid sources in aquafeeds, the lipid composition should be targeted to achieve proper fatty acid profiles to meet the requirements of fish and maximise human health benefits ${ }^{(54)}$. Over the past 20 years evidence has increased that $n$-3 LC-PUFA, in particular EPA and DHA, have unique nutritional and health benefits to the human consumer ${ }^{(55-64)}$. As salmon have the ability to store considerable amounts of $n$-3 LC-PUFA in their flesh, they are considered an excellent source of these key essential fatty acids.

However, excess intake of $n$ - 6 PUFA in humans, in particular linoleic acid $(18: 2 n-6)$, has been associated with many disorders including CVD, cancer, and inflammatory and autoimmune disease ${ }^{(65)}$. It is thought that $n-6$ PUFA, in particular linoleic acid, is excessive in most Western diets, 
Table 1. Fatty acid profiles $(\mathrm{g} / 100 \mathrm{~g})$ of possible plant or vegetable replacement oils for fish oil

\begin{tabular}{|c|c|c|c|c|c|c|c|c|c|}
\hline & Palm oil ${ }^{*}$ & Rapeseed oil† & Linseed oilł & Sunflower-seed oil§ & Olive oill| & Soya oilq & Echium oil ${ }^{\star \star}$ & Thraustochytrid oil†† & Fish oilłł \\
\hline $14: 0$ & $1 \cdot 2$ & 0.0 & 0.0 & 0.0 & 0.0 & 0.0 & 0.0 & 8.9 & $6 \cdot 2$ \\
\hline $16: 0$ & 46.7 & 4.7 & $6 \cdot 3$ & 6.4 & $10 \cdot 8$ & 9.7 & 7.5 & $26 \cdot 1$ & $16 \cdot 4$ \\
\hline $18: 0$ & $5 \cdot 2$ & $2 \cdot 1$ & $5 \cdot 1$ & $4 \cdot 1$ & 3.3 & 3.5 & 3.6 & 0.8 & 3.5 \\
\hline Other SFA & 0.3 & 0.6 & 0.0 & 1.5 & 0.6 & 0.2 & 0.0 & 1.0 & 1.2 \\
\hline Total SFA & 53.5 & 7.4 & 11.4 & $12 \cdot 0$ & $14 \cdot 6$ & 13.4 & $11 \cdot 2$ & $36 \cdot 7$ & $27 \cdot 3$ \\
\hline $16: 1 n-7 c$ & 0.0 & 0.0 & 0.0 & 0.0 & 0.7 & 0.7 & 0.0 & 0.6 & 8.2 \\
\hline $18: 1 n-9 c$ & 33.8 & $58 \cdot 3$ & $18 \cdot 3$ & $25 \cdot 3$ & $75 \cdot 4$ & 22.5 & $17 \cdot 2$ & 1.3 & $21 \cdot 1$ \\
\hline $18: 1 n-7 c$ & 1.3 & 4.3 & 1.3 & $2 \cdot 0$ & 2.5 & 1.8 & 1.0 & 0.4 & 3.6 \\
\hline $20: 1 n-9$ & 0.0 & 1.1 & 0.0 & 0.0 & 0.0 & 0.0 & 0.8 & 0.1 & 3.8 \\
\hline Other MUFA & 0.0 & 0.0 & 0.0 & 0.0 & 0.0 & 0.0 & 0.9 & 0.2 & $6 \cdot 2$ \\
\hline Total MUFA & 35.1 & 63.7 & $19 \cdot 6$ & $27 \cdot 2$ & 78.6 & $25 \cdot 0$ & $19 \cdot 9$ & $2 . \overline{5}$ & $42 . \overline{9}$ \\
\hline $18: 3 n-3$ & 0.0 & $7 \cdot 3$ & $53 \cdot 3$ & 0.0 & 0.0 & $6 \cdot 4$ & $28 \cdot 1$ & 0.1 & 0.6 \\
\hline $18: 4 n-3$ & 0.0 & 0.0 & 0.0 & 0.0 & 0.0 & 0.0 & 11.4 & 0.4 & 1.5 \\
\hline $20: 4 n-3$ & 0.0 & 0.0 & 0.0 & 0.0 & 0.0 & 0.0 & 0.0 & 1.0 & 1.0 \\
\hline $20: 5 n-3$ & 0.0 & 0.0 & 0.0 & 0.0 & 0.0 & 0.0 & 0.0 & $2 \cdot 2$ & $12 \cdot 7$ \\
\hline $22: 5 n-3$ & 0.0 & 0.0 & 0.0 & 0.0 & 0.0 & 0.0 & 0.0 & 0.7 & 1.7 \\
\hline $22: 6 n-3$ & 0.0 & 0.0 & 0.0 & 0.0 & 0.0 & 0.0 & 0.0 & $36 \cdot 7$ & $7 \cdot 3$ \\
\hline Other $n-3$ & 0.0 & 0.0 & 0.0 & 0.0 & 0.0 & 0.0 & 0.0 & 0.0 & 0.5 \\
\hline Total $n-3$ & 0.0 & $7 \cdot 3$ & 53.3 & 0.0 & 0.0 & $6 \cdot 4$ & 39.6 & $41 \cdot 1$ & $25 \cdot 3$ \\
\hline $18: 2 n-6$ & $11 \cdot 4$ & $21 \cdot 6$ & $15 \cdot 7$ & $60 \cdot 7$ & $6 \cdot 8$ & $55 \cdot 2$ & 19.5 & 0.6 & 3.4 \\
\hline $18: 3 n-6$ & 0.0 & 0.0 & 0.0 & 0.0 & 0.0 & 0.0 & $9 \cdot 8$ & 0.3 & 0.0 \\
\hline $20: 3 n-6$ & 0.0 & 0.0 & 0.0 & 0.0 & 0.0 & 0.0 & 0.0 & 0.5 & 0.0 \\
\hline $20: 4 n-6$ & 0.0 & 0.0 & 0.0 & 0.0 & 0.0 & 0.0 & 0.0 & 2.4 & 1.0 \\
\hline $22: 5 n-6$ & 0.0 & 0.0 & 0.0 & 0.0 & 0.0 & 0.0 & 0.0 & $15 \cdot 8$ & 0.0 \\
\hline Other $n-6$ & 0.0 & 0.0 & 0.0 & 0.0 & 0.0 & 0.0 & 0.0 & 0.0 & 0.1 \\
\hline Total $n-6$ & 11.4 & 21.6 & $15 \cdot 7$ & $60 \cdot 7$ & 6.8 & $55 \cdot 2$ & 29.3 & $19 \cdot 6$ & 4.5 \\
\hline$n-3: n-6$ & 0.0 & 0.3 & 3.4 & 0.0 & 0.0 & 0.1 & 1.3 & $2 \cdot 1$ & $5 \cdot 6$ \\
\hline $\begin{array}{l}\text { Oil price January } \\
2007 \text { (\$US/tonne)§§ }\end{array}$ & 572 & 712 & 759 & 657 & 3245 & 641 & $4000-8000|| \mid$ & $20000-100000|| \mid$ & 817 \\
\hline $\begin{array}{l}\text { Oil price January } \\
2008 \text { (\$US/tonne)§§ }\end{array}$ & 1039 & 1569 & 1475 & 1645 & 3894 & 1174 & $4000-8000|| \mid$ & $20000-100000||||$ & 1615 \\
\hline
\end{tabular}

* Aoroma, Hallam, Vic, Australia.

† Steric Trading Pty Ltd, Villawood, NSW, Australia.

Melrose Laboratories, Mitcham, Vic, Australia.

Foods, Mascot, NSW, Australia.

IIsland Olive Grove, Cambridge, Tasmania, Australia.

Carolina Soy Product, Warsaw, NC, USA

${ }^{* *}$ Croda Chemicals, East Yorkshire, UK.

†† Martek, Columbia, MD, USA.

ł¥From jack mackerel (Trachurus symmetricus L.), Skretting Australia, Cambridge, Tasmania, Australia.

$\S \S$ Prices taken as an average of January oil prices in 2007 and 2008 from Hamburg market prices, OIL WORLD ISTA Mielke GmbH, Hamburg, Germany.

\|\| Estimated current costs; however, costs may reduce when the volume of production increases. 
which are dominated by vegetable oils and processed foods. It is increasingly recognised that a greater ratio of $n-3: n-6$ PUFA plays a positive role in human health ${ }^{(65-67)}$ and is also important in aquafeeds, because this ratio best represents the natural diets of salmon ${ }^{(25)}$. Eating oily, $n-3$ LC-PUFA-rich fish such as salmon is proposed to be a good way to improve the dietary $n-3: n-6$ ratio ${ }^{(68)}$.

\section{Biosynthetic pathway of n-3 and n-6 PUFA}

Atlantic salmon can naturally biosynthesise $n$-3 LC-PUFA from dietary precursors (Fig. 1). Understanding and utilising this biosynthetic capacity through the provision of different precursors may ensure that farmed salmon receive their required $n-3$ LC-PUFA. Salmon lack $\Delta 12$ and $\Delta 15$ fatty acid desaturases and cannot produce linoleic acid and $\alpha$-linolenic acid (ALA; 18:3n-3) from the precursor oleic acid $(18: 1 n-9)^{(24)}$. However, salmon can biosynthesise dietary ALA into $n$-3 LC-PUFA ${ }^{(24)}$. Atlantic salmon are anadromous: the adult fish live in the sea, but breed and have their early development stages in fresh water. The ability of Atlantic salmon to biosynthesise $n$-3 LC-PUFA from precursors changes throughout their life cycle ${ }^{(69)}$.

The conversion of ALA to $n$-3 LC-PUFA has been demonstrated in freshwater fish, which have high concentrations of ALA and limited DHA in their natural diet ${ }^{26,70,71)}$. However, the conversion of ALA to EPA and DHA is inefficient in marine fish, which have high concentrations of LC-PUFA in their natural diet ${ }^{(72)}$. Therefore the evolutionary pressure of fatty-acid availability has affected the ability of fish to biosynthesise $n$-3 LC-PUFA. There have been many studies to determine the capacity of Atlantic salmon to biosynthesise $n$-3 LC-PUFA from precursor dietary fatty acids ${ }^{(36,69,73-81)}$. Salmon have shown a very limited capacity to produce $n-3 \mathrm{LC}$ PUFA from ALA in both in vivo and in vitro trials $^{(36,69,73-75,77-80)}$. However, there has been limited research on other biosynthetic precursors such as stearidonic acid (SDA; $18: 4 n-3)$ in salmon ${ }^{(76,81,82)}$. Understanding the complex interactions between gene expression, synthesis of enzymes (protein expression) and fatty acid composition will give a better understanding of biological responses at the cellular level, including, for example, how Atlantic salmon endogenously produce, use and store $n$-3 LC-PUFA.

\section{Advantages and disadvantages of vegetable- or plant-based oils}

The major advantages that vegetable oils have over fish oil as ingredients in aquafeeds are that they are produced in large volumes, are renewable, can be reliably sourced and importantly are currently less expensive. However, the main disadvantage is that they do not contain any $n-3$ LC-PUFA or $n$-6 LC-PUFA and therefore they are, as a sole oil source, unable to meet the nutritional requirements for these components by Atlantic salmon. Vegetable oils generally have high concentrations of oleic acid, linoleic acid and in some instances ALA.

Other disadvantages of terrestrial oils include significant environmental, social and economic issues surrounding their production ${ }^{(83,84)}$ including increasing oil and grain prices due to competing global demand for biofuel, and an associated acceleration in unsustainable or inappropriate land-use practices, for example replacing rain forest with palm oil plantations ${ }^{(83,84)}$.

Nonetheless, aquafeed producers are increasingly using blends of vegetable oils. Blending oils gives the feed producers flexibility to meet dietary nutritional requirements and also allows seasonal adjustment of diets in response to factors such as cost and availability. The major sources of vegetable oils that have been extensively researched for Atlantic salmon include sunflowerseed $^{(16,32)}$, linseed ${ }^{(33-36)}$ rapeseed $^{(34,37-40)}$, soyabean ${ }^{(35,41)}$, olive $^{(32,38)}$ and palm oil ${ }^{(13,32,35,39)}$. The fatty acid profiles of the major replacement oils for aquaculture diets differ greatly (Table 1).

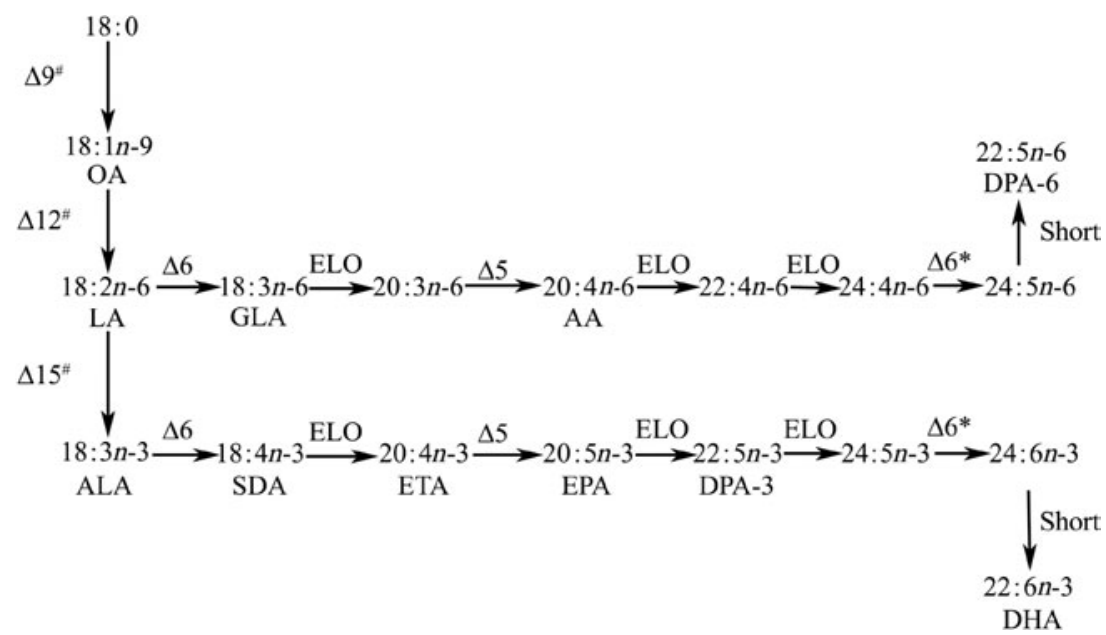

Fig. 1. Representation of the $n-3$ and $n-6$ long-chain $\left(\geq C_{20}\right)$ PUFA biosynthetic pathways from their $C_{18}$ fatty acid precursors in Atlantic salmon (Salmo salar L.). OA, oleic acid; LA, linoleic acid; $\Delta 5, \Delta 6$ and $\Delta 6^{*}$, fatty acyl desaturases; GLA, $\gamma$-linolenic acid; ELO, fatty acyl elongases; AA, arachidonic acid; DPA-6, docosapentaenoic acid $(n-6)$; Short, fatty acyl peroxisomal chain shortening; ALA, $\alpha$-linolenic acid; SDA, stearidonic acid; ETA, eicosatetraenoic acid; DPA-3, docosapentaenoic acid $(n-3) . \Delta 6^{*}$ may or may not be the same desaturase enzyme as $\Delta 6 . \Delta 9^{\#}, \Delta 12^{\#}$ and $\Delta 15^{\#}$ are not present in Atlantic salmon. Adapted from Tocher $^{(24)}$. 
The fatty acid profile of vegetable oils can vary with location, season and species. Alongside fatty acid profile, cost and production characteristics of these oils are considerable factors in their selection as ingredients in aquafeeds. Globally, soya and palm are the most abundant oil crops and have the lowest market price. The cheapest oils for aquafeeds in non-European Union countries are poultry and animal fats (lard, \$US 930 per tonne, Hamburg market prices, January 2008, OIL WORLD ISTA Mielke GmbH, Hamburg, Germany) in which the fatty acid profiles are dominated by SFA, in particular palmitic acid $(16: 0)$ and stearic acid $(18: 0)$. There are significant economic benefits of including poultry and animal fats in aquafeeds, but regulations in Europe following the outbreaks of BSE forbid the use of animal lard in aquafeeds. The rise in vegetable oil prices shown in Table 1, and their predicted increase in the future, is largely attributed to increased use and demand for oil in biofuels ${ }^{(84)}$.

\section{Phytosterols}

Minor components of vegetable oil that are not present in the natural diets of fish need to be investigated and monitored. For example, a potential benefit of the increasing replacement of fish oil and meal with plant-based ingredients in salmon aquafeeds is the increased amounts of phytosterols in the fish diet. Phytosterols are naturally occurring molecules found in vegetable oils and meals which are structurally related to cholesterol ${ }^{(85)}$. Phytosterols are known to affect cholesterol metabolism and have been shown to reduce LDL-cholesterol levels in humans, reducing the risk of $\mathrm{CHD}^{(85-87)}$. Phytosterols are lipophilic and have been introduced to margarines, butters, spreads and breakfast cereals and promoted as 'functional foods' to reduce $\mathrm{CHD}^{(88-90)}$. With the increased use of vegetable oils in aquafeeds, increased natural abundances of phytosterols will occur in Atlantic salmon diets. There has only been one investigation of the digestion, accumulation and metabolism of phytosterols in Atlantic salmon when fed replacement diets containing plant-based oils ${ }^{(91)}$. That study showed that Atlantic salmon were able to digest and accumulate low levels of phytosterols ${ }^{(91)}$. The low amount of phytosterols available in the diet, coupled with their low digestibility, suggests at this stage that Atlantic salmon are unlikely to be a major delivery source of this cholesterol-lowering agent. However, in combination with the health benefits of $n-3 \mathrm{LC}$ PUFA, phytosterols may act in unison to increase the benefits of eating farmed salmon for the consumer. Minor components of vegetable oils such as phytosterols need to be monitored to determine whether they have positive or negative effects not only for the consumer, but also for fish health.

\section{Regiospecificity of fatty acids}

Lipids are important molecules in the body for storing energy and for maintaining cell membrane integrity. Regiospecificity refers to how individual fatty acids are positioned on the glycerol backbone of both storage TAG and membrane polar lipids. Regiospecificity of lipids plays an important role in their function and bioavailability.
The bioavailability of $n-3$ LC-PUFA is of vital importance if Atlantic salmon is to be marketed as a good source of $n-3$. Regiospecific characteristics of dietary and possibly endogenously biosynthesised $n$-3 LC-PUFA stored as TAG by Atlantic salmon is yet to be understood fully by fish nutritionists. Therefore, it is important to assess the regiospecificity of novel sources of $n$-3 LC-PUFA oil. Traditional profiling of lipid class and fatty acid composition provides important information, but does not reveal the regiospecific nature of the molecules, which can play a key role in their function ${ }^{(92,93)}$. With advances in analytical and computing facilities, new techniques and methods can be used to examine lipids with the emphasis on the regiospecific distribution of fatty acids.

The middle $s n$ - 2 position of the storage TAG molecule is thought to be the most bioavailable position for the digestion of particular fatty acids. This was first shown in fat absorption by infants fed breast or formulated milk ${ }^{(94)}$. How Atlantic salmon regiospecifically store $n$-3 LC-PUFA has the potential to affect the bioavailability of fatty acids for the human consumer. Structural lipids, such as polar lipids, are important components of cell membrane structure. The composition of the molecular species in the cell membrane can be influenced by many factors including temperature and diet ${ }^{(95)}$. The composition of cell membranes has a major effect on the health of the cell and therefore the health of the fish. To date, limited research has been conducted to identify changes in the regiospecific composition of membrane lipids and TAG in Atlantic salmon as a result of changes in the fatty acid profile of their diet ${ }^{(96)}$. Regiospecific analysis of the lipid profiles of Atlantic salmon has shown recently that DHA has a high affinity for the $s n-2$ (middle) position in both the TAG and polar lipid fractions ${ }^{(97)}$.

\section{Influence of temperature on lipids}

Temperature has a major influence on the membrane and storage lipids of exothermic animals, such as Atlantic salmon, which need to adapt to seasonal and occasionally abrupt changes in environmental temperature ${ }^{(72,98-100)}$. The Tasmanian Atlantic salmon industry commonly encounters temperatures (over $19^{\circ} \mathrm{C}$ ) that approach the upper threshold for salmon survival ${ }^{(31)}$. A possible outcome of climate change is increased sea temperature, which may affect aquaculture not only in Tasmania but worldwide. Replacement oil blends may assist by adapting the fatty acid profiles of salmon diets to meet the different nutritional requirements for raised temperatures.

Fish may exploit the structural diversity of lipids within their membranes to adapt to change in ambient water temperature. Membrane lipids may adapt in several ways to a change in temperature: by altering the unsaturation and chain-length of the fatty acids ${ }^{(101)}$; by changing the distribution of fatty acids within the phospholipid molecules ${ }^{(102,103)}$; by altering the composition of the polar head group of the phospholipids ${ }^{(104,105)}$. In general, colder temperatures lead to an increase in unsaturation in gill lipids, thus maintaining membrane fluidity ${ }^{(103,106)}$. Most studies have investigated temperature influence on Atlantic salmon lipids within the range of $2-12^{\circ} \mathrm{C}^{(41,107-109)}$, but only one has examined salmon at higher temperatures such 
as $19^{\circ} \mathrm{C}^{(97)}$. An increased water temperature of $19^{\circ} \mathrm{C}$ resulted in adaptation of both structural and storage lipids with significant reduction in PUFA occurring, in particular in the tissue concentrations of $\mathrm{EPA}^{(97)}$. As water temperatures rise, there is reduced need for high levels of $n$-3 LC-PUFA in polar lipids to maintain optimal cell membrane function. The converse is true for decreasing water temperatures. This suggests that changes in Atlantic salmon diets, in particular the amount of $n-3$ LC-PUFA, during periods of high water temperature may maintain the health and performance of fish. With global water temperatures increasing it is pertinent to monitor membrane structure and oil storage in salmon at higher temperatures.

Temperature plays a significant role in the digestibility of lipids in salmon diets ${ }^{(108,110-112)}$. Reduced water temperature decreases the digestibility of SFA and therefore changing the dietary source of oil may have implications during winter conditions. Highly saturated oils, such as palm, have been demonstrated to have reduced digestibility at very low water temperature; however, the digestibility of MUFA and PUFA was not affected ${ }^{(110)}$. The fatty acid profile of novel sources of oil needs to be considered, in regard to digestibility, when formulating diets.

\section{Potential sources of n-3 long-chain PUFA for aquaculture}

Other than traditional fish oil sources, the current and future possible sources of oil that contain beneficial essential fatty acids or their precursors are:

(1) Other marine sources including by-catch and marine invertebrates such as krill and copepods;

(2) Vegetable oils that contain biosynthetic precursors that can be used by Atlantic salmon to biosynthesise $n-3$ LC-PUFA;

(3) Several different microbial taxa at the base of the marine food chain that produce single-cell oils that are rich in $n$-3 LC-PUFA;

(4) GM organisms including single-celled micro-organisms and terrestrial plants that have undergone genetic modification and contain enriched amounts of $n-3$ LC-PUFA.

Each of these sources of oil will be discussed in turn.

\section{Other marine sources}

Improving our seafood processing byproducts as well as an increased use of by-catch may create a possible source of $n$-3 LC-PUFA oil for aquafeeds. Seafood processing byproducts exist in large quantities (over $30 \%$ of processed seafood is inedible) and can contain high levels of LC $n-3$ oils, including EPA and DHA. Therefore, byproducts from seafood processing operations could supply, in part, the $n-3$ LC-PUFA required for aquaculture. However, before the use of recycled oil and meal from seafood processing can occur, several factors need to be assessed. These include understanding the risk of prions and other disease transmission vectors associated with feeding byproducts from one species back to the same or similar species ${ }^{(113)}$. As previously stated, regulations in Europe forbid the use of land animal products in aquafeeds. It is yet to be determined whether the benefits (ecological and economic) outweigh the risks (human health) of using various types of seafood byproducts as feed. Furthermore, contaminants in oil from seafood byproducts, such as PCB and dioxins, have the potential to bioaccumulate in farmed fish ${ }^{(45,46)}$. Careful monitoring of these contaminants in seafood byproducts and oil derived from them is needed. Finally, the socio-economic and environmental aspects of the use of seafood byproducts need to be assessed before they can be used in aquafeeds.

Other marine sources, such as marine invertebrates, may be a future source of $n$-3 LC-PUFA oil. Southern Ocean krill (Euphausia superba) biomass is estimated at up to 700 million metric tonnes, and the current regulatory catch quota is almost 6 million metric tonnes ${ }^{(114,115)}$. However, due to factors such as the remoteness of the fishery, the current catch is only 0.2 million metric tonnes ${ }^{(116)}$. Krill contain oil which has high concentrations of EPA and DHA plus high levels of phospholipids and antioxidants such as the carotenoid, astaxanthin ${ }^{(115,117)}$. The fatty acid profile of krill oil can vary markedly with the region and time of year of harvest, with other factors also influencing its profile ${ }^{(118,119)}$. Considerable care will be required with management practices in the setting of local catch limits for krill harvest to protect not only this sensitive species, but also key Southern Ocean predators. Krill is at the base of the Southern Ocean's food chain, and is also particularly sensitive to environmental changes including climate change ${ }^{(116,120)}$. Over-fishing of krill, particularly concentrated fishing efforts in localised regions, could severely undermine the food web and devastate marine life ${ }^{(120)}$. As such, increasing fishing pressure for krill is worrisome and the catch and ecological consequences should be closely monitored.

Zooplankton, specifically copepods, may also provide a minor alternative source of $n-3$ LC-PUFA oil. The commercial harvesting of wild copepods is not expected to meet the demand, quality and constant supply of $n-3$ LCPUFA $^{(121)}$. Cultured copepods may be a future source of feed including oil; however, the scale of production to supply aquaculture's growing demand for quality n-3 LCPUFA-rich oil is beyond its scope ${ }^{(121)}$. However, copepod oil, more likely the total biomass, may provide niche products for segments of the aquaculture industry in particular in larval rearing ${ }^{(121-123)}$.

\section{Biosynthetic precursors of n-3 long-chain PUFA}

As mentioned above, fish have an endogenous capacity via fatty acid desaturase and elongase enzymes to biosynthesise $n$-3 LC-PUFA from ALA. The pathways are quantitatively important in freshwater fish, but activity levels are very low in marine species ${ }^{(24,69)}$. Understanding and utilising biosynthetic precursors further along the LC $n-3$ pathway may provide renewable and sustainable options from the use of specialised vegetable oils for future aquafeeds. Plants such as Patterson's curse (Echium plantagineum L.) and blackcurrant (Ribes nigrum L.) have a $\Delta^{6}$ desaturase gene that produces the $n-3$ LC-PUFA biosynthetic precursor SDA from ALA. Echium oil from Patterson's curse has an SDA level $>10 \%$ depending on the strain (Table 1). It has been suggested that the $\Delta^{6}$ desaturation of ALA to SDA is the 
limiting step in the biosynthetic pathway of $n-3$ LC $\mathrm{PUFA}^{(124)}$. In this case, dietary SDA bypasses the initial rate-limiting $\Delta^{6}$ desaturase step in the $n$-3 LC-PUFA biosynthetic pathway (Fig. 1) and potentially enables greater biosynthesis of EPA and DHA via non-limiting steps. For this to occur, subsequent desaturase enzymes must also be present in large enough amounts.

It has been recently shown that freshwater Atlantic salmon parr can maintain concentrations of $n$-3 LC-PUFA, in particular EPA and DHA, in muscle tissue over a 6-week period when fed a diet containing SDA, but with only trace levels of $n-3$ LC-PUFA $^{(81)}$. This result indicated that SDArich aquafeeds may have potential as an alternative to replace $n$-3 LC-PUFA sources such as fish oil in freshwater aquaculture; however, this was only a short trial and occurred over the period before smolting, which has been shown to coincide with a period of peak $n$-3 LC-PUFA production $^{(69)}$. Smolting involves a series of morphological, physiological and behavioural changes which include both increased lipid deposition and increased accumulation of LC-PUFA, in particular arachidonic acid, before saltwater transfer ${ }^{(125,126)}$. During this freshwater parr stage, the use of dietary precursor (SDA) oils such as Echium oil may prove most beneficial in aquafeeds.

Further research on Atlantic salmon smolt fed SDA demonstrated an up-regulated expression of genes involved in fatty acid synthesis, which affected the concentration of the direct biosynthetic product (eicosatetraenoic acid; 20:4 $n-3)$ in all tissues ${ }^{(127)}$. However, the increased gene expression with use of the SDA-rich diet is not enough to maintain concentrations of $n-3$ LC-PUFA in seawater Atlantic salmon fed SDA at equivalent amounts to those in fish fed with fish oil ${ }^{(127)}$. Results with Atlantic salmon smolt are analogous with other species of fish, the marine Atlantic cod (Gadus morhua L.) and a salmonid species the Arctic charr (Salvelinus alpinus L.), that have shown SDA conversion to eicosatetraenoic acid (20:4n-3), but not to EPA and $\mathrm{DHA}^{(128,129)}$. Selective breeding programmes with Atlantic salmon and other salmonoids have focused on characteristics such as health and growth requirements, but increasingly contain product quality factors such as flesh colour, fat content and fat distribution ${ }^{(130)}$. In the future, selection traits may be widened to include enhanced biosynthesis of $n$-3 LC-PUFA and/or an ability to store large amounts of the $n-3$ LC-PUFA-rich oil in the fillet. Family lines of salmon with an elevated ability for $n-3$ LC-PUFA biosynthesis and/or storage may lead to a reduced need for the provision of dietary $n$ - 3 LC-PUFA.

The cost and availability of an SDA-rich oil source, such as Echium oil, is at present not economically viable for aquaculture. The current price of SDA-rich oil from Patterson's curse is $2 \cdot 5-5$ times the price of fish oil (Table 1). In Australia, Patterson's curse is an introduced pest species and considered a noxious weed. Despite a significant proportion of southern Australian agricultural land being covered by Patterson's curse, there are presently no companies in Australia looking to use this resource for its oil content. However, the amount of oil available to be extracted from Patterson's curse is minor compared with commercial oil crops. The only commercially viable source of SDA-rich oil may be through the genetic modification of oilseed crops (see below). Furthermore, the ability of salmon and or other species to digest, accumulate and biosynthesise SDA into longer $n$-3 LC-PUFA needs to be further assessed before it can be considered as a dietary ingredient for aquafeeds.

\section{Single-cell oils}

Single-cell oils provide a novel and renewable source of essential fatty acids, in particular EPA and DHA. Single-cell organisms, including thraustochytrids, diatoms, other microalgae and some marine bacteria are the $n$ - 3 LCPUFA 'biofactories' of the ocean. Thraustochytrids are heterotrophic protists, commonly found in marine and other saline environments; they can be detritivores, bacterivores and/or parasites ${ }^{(131)}$. Originally thought to be closely related to primitive fungi, thraustochytrids have more recently been assigned to the subclass Thraustochytridea (Chromista, Heterokonta), aligning them with heterokont algae such as diatoms and brown algae ${ }^{(132)}$. Thraustochytrids can produce a number of $n$-3 LC-PUFA, especially DHA. Thraustochytrids show potential as a source of oil for aquaculture ${ }^{(31,131,133-136)}$. Large-scale culture of thraustochytrids may be suitable for commercial aquafeeds as they produce a relatively high biomass and have a high percentage of $n-3$ LC-PUFA-rich lipid ${ }^{(131)}$. Optimising strain selection and growth conditions can provide single-cell oils with specific qualities such as high DHA (concentrations up to $60 \%$ ), low n-6 (in particular docosapentaenoic acid, DPA-6, 22 : 5n-6), high total $n-3$ LC-PUFA and high $n-3: n-6 \operatorname{ratios}^{(137)}$. Thraustochytrid biomass (for example, the product Algamac) is already being used commercially as an enriched feed for rotifers (Brachionus spp.) and brine shrimp (Artemia) before feeding these live feeds to finfish larvae ${ }^{(133-135)}$ and as a fish oil replacement in Atlantic salmon nutrition trials ${ }^{(31,136)}$. The replacement of fish oil with $100 \%$ thraustochytrid oil in Atlantic salmon parr diets has been demonstrated, without any detriment to growth, to significantly increase the concentrations of DHA in muscle tissue $^{(136)}$. Thraustochytrid oil (Table 1) from the species Schizochytrium L., has a high concentration of DHA (35\%).

Single-cell oils, such as oil from thraustochytrids, provide a major renewable source of $n$-3 LC-PUFA for aquaculture. These organisms could potentially provide a source of $n-3$ LC-PUFA without any foreseeable negative impact on wild fish stocks. Currently, manufacturers of single-cell oils do not have sufficient production capacity and the oils are viewed as too expensive to be considered for use as a replacement oil in diets for Atlantic salmon, although the use of thraustochytrid biomass is now thought to be economically feasible for prawns (Browdy et al. ${ }^{(138)}$; B Bullis, personal communication). There is still considerable scope for the discovery or development of novel strains with other advantageous properties including high $n$ - 3 LC-PUFA concentrations. With the continual discovery of new strains and improvements in fermentation and molecular engineering techniques, it may be possible to produce single-cell oils or biomass with sufficient amounts of $n-3$ LC-PUFA and at a price suitable to meet the growing demand in aquaculture. It is likely that increased use in biomedical fields will cover the high initial cost of this biotechnology allowing 
aquaculture to access it when production capacity is increased and, importantly, as the price is reduced. Singlecell biomass rather than extracted oil is a logical candidate for aquafeeds as it provides $n$-3 LC-PUFA-rich oil with accompanying marine proteins at a significantly lower price due to a reduction of the processing costs.

\section{Genetic modification of oils}

Transgenic oilseed crops and micro-organisms that are engineered to produce the major $n-3$ LC-PUFA by the insertion of various genes encoding desaturases and/or elongases have been suggested as a source of $n-3$ LCPUFA $^{(139,140)}$. However, the requirement for coordinate expression and activity of five or more new enzymes encoded by genes from possibly diverse sources has made this goal difficult to achieve and only low yields have generally been obtained ${ }^{(139,141,142)}$.

A gene encoding the $\Delta^{6}$ desaturase isolated from borage (Borago officinalis) was expressed in transgenic tobacco and Arabidopsis, resulting in the production of $\gamma$-linolenic acid and SDA, the direct precursors of LC-PUFA ${ }^{(143,144)}$. This initial research provided only the first step to $n-3$ LCPUFA, but may provide a renewable source of SDA for aquaculture and other uses. Recently more genes encoding the whole pathway have produced $\mathrm{EPA}^{(145)}$ and $\mathrm{DHA}^{(139)}$, in crops or model plants, including oilseeds. In the model plant Arabidopsis, the insertion of five genes resulted in the first oil with $\mathrm{DHA}^{(139)}$. That study observed a total LC-PUFA content (arachidonic acid + EPA + DHA) of $4.2 \%$. This has subsequently been increased to close to $8 \%$ (SP Singh, SS Robert, XR Zhou, JR Petrie, SI Blackburn, PM Mansour, PD Nichols and Q Liu, unpublished results). Further research using different genes and seed-specific promoters with soyabean has produced an EPA content of $19.5 \%$ and a DHA content of $3 \cdot 3 \%^{(146)}$. These two examples demonstrate the complicated nature of engineering multi-genes to produce a sustainable land plant source of $n-3$ LC-PUFArich oil.

Nonetheless, GM plants may in the future provide the most economically viable source of $n$-3 LC-PUFA-rich oil for aquaculture. It is estimated that the cost and availability of oils from GM plants would be similar to that of currently available commercial oilseed crops such as rapeseed and soya. Research in this area has the potential for significant commercial, health, social and environmental benefits. However, consumer and industry acceptance of this biotechnology and the requirement for passing health and safety requirements set by regulatory bodies will be needed for oils from GM plants before they can be used by the aquaculture industry. Recent assessments of perceived consumer acceptance of GM land-plant n-3 LC-PUFA technologies in Australia and the USA have reported that farmed fish were a preferred delivery mechanism compared with capsules or functional foods ${ }^{(147,148)}$. Ultimately, as demand for fish oil intensifies, as knowledge about fishing impacts and benefits to human health of $n$-3 LC-PUFA increases, and the potential for salmon prices to decrease occurs due to reduced ingredient cost, consumers may eventually accept oil from a GM crop as an ingredient of aquafeeds.

\section{Future security of n-3 long-chain PUFA oils and sustainable} aquaculture

Having access to secure sources of $n$-3 LC-PUFA-rich oils is vital for the continued sustainability and growth of the intensive aquaculture industry. The future use of these $n-3$ LC-PUFA-rich oils will depend on the cost and availability of fish oil as a commodity. It is yet unknown whether a premium $n$-3 oil crop (to include $n$-3 LC-PUFA via GM or increased $n-3: n-6$ ratio via selective breeding and management methods) would be economically viable. However, as fish oil and grain prices rise, alternative sources of $n$-3 LC-PUFA-rich oils are becoming more financially feasible. Single-cell biomass with high amounts of $n$-3 LC-PUFA will provide an option, but the current high production cost limits their immediate use. New n-3 LC-PUFA oils from GM land plants are still in development, with trials including field planting, fish and animal feeding, toxicity and other assessments required before the large-scale consideration of their use by aquafeed companies.

In summary, the short-term forecast for aquafeeds rests in the careful management of the use of fish oil from wild fisheries, the use of vegetable and other oils in blends, and the use of suitable feeding regimens including finishing diets containing higher levels of the $n$ - 3 LC-PUFA oils than in the longer grow-out phase. These changing and developing practices will be continuously evaluated as new technologies become available to prevent impacts on wild fish stocks, and to increase resource security and market feasibility. Aquaculture will need to increase efforts to find new sources of $n$-3 LC-PUFA, in particular for intensive rearing of marine carnivorous species. Whether replacement sources will be derived from single-cell biomass, from oil from GM land plants, or a combination of the two is yet to be determined, but will ultimately depend on scientific developments, social acceptance, community needs and governmental policy.

\section{Acknowledgements}

M. M. was supported by an Australian postgraduate award (APA) and a CSIRO Food Futures Flagship postgraduate award. There are no conflicts of interest.

\section{References}

1. Naylor RL, Goldburg RJ, Primavera JH, et al. (2000) Effect of aquaculture on world fish supplies. Nature 405, 1017-1024.

2. Black KD (2001) Sustainability of aquaculture. In Environmental Impacts of Aquaculture, pp. 199-212 [KD Black, editor]. Sheffield: Sheffield Academic Press.

3. Pauly D, Christensen V, Guenette S, et al. (2002) Towards sustainability in world fisheries. Nature 418, 689-695.

4. Worm B \& Myers RA (2004) Managing fisheries in a changing climate. Nature 429, 15.

5. Pauly D \& Christensen V (1995) Primary production required to sustain global fisheries. Nature 374, 255-257.

6. Tegner MJ \& Dayton PK (1999) Ecosystem effects of fishing. Trends Ecol Evol 14, 261-262. 
7. Tacon AGJ (2003) Aquaculture production trends analysis. In Review of the State of World Aquaculture, FAO Fisheries Circular no. 886, vol. Rev. 2, pp. 5-29 [R Subasinghe and S McGladdery, editors]. Rome: FAO.

8. Schwartzlose RA, Alheit J, Bakun A, et al. (1999) Worldwide large-scale fluctuations of sardine and anchovy populations. S Afr J Mar Sci 21, 289-347.

9. Lehodey P, Alheit J, Barange M, et al. (2006) Climate variability, fish, and fisheries. J Clim 19, 5009-5030.

10. Gutierrez M, Swartzman G, Bertrand A, et al. (2007) Anchovy (Engraulis ringens) and sardine (Sardinops sagax) spatial dynamics and aggregation patterns in the Humboldt Current ecosystem, Peru, from 1983-2003. Fish Oceanog 16, 155-168.

11. Barlow S (2000) Fishmeal and fish oil: sustainable feed ingredients for aquafeeds. Glob Aquac Advocate 3, 85-86.

12. Sanchez G, Calienes R \& Zuta S (2000) The 1997-98 El Nino and its effects on the coastal marine ecosystem off Peru. Cali Coop Oceanic Fish Invest Rep 41, 62-86.

13. Bell JG, Henderson RJ, Tocher DR, et al. (2002) Substituting fish oil with crude palm oil in the diet of Atlantic salmon (Salmo salar) affects muscle fatty acid composition and hepatic fatty acid metabolism. J Nutr $\mathbf{1 3 2}$ $222-230$.

14. Anonymous (2007) GLOBEFISH Seafood Highlights 2007. Rome: GLOBEFISH.

15. Sargent JR \& Tacon AGJ (1999) Development of farmed fish: a nutritionally necessary alternative to meat. Proc Nutr Soc 58, 377-383.

16. Bransden MP, Carter CG \& Nichols PD (2003) Replacement of fish oil with sunflower oil in feeds for Atlantic salmon (Salmo salar L.): effect on growth performance, tissue fatty acid composition and disease resistance. Comp Biochem Physiol B 135, 611-625.

17. Bell JG, Dick JR \& Sargent JR (1993) Effect of diets rich in linoleic or $\alpha$-linolenic acid on phospholipid fatty acid composition and eicosanoid production in Atlantic salmon (Salmo salar). Lipids 28, 819-826.

18. Ng WK, Tocher DR \& Bell JG (2007) The use of palm oil in aquaculture feeds for salmonid species. Eur J Lipid Sci Tech 109, 394-399.

19. Torstensen BE, Bell JG, Rosenlund G, et al. (2005) Tailoring of Atlantic salmon (Salmo salar L.) flesh lipid composition and sensory quality by replacing fish oil with a vegetable oil blend. J Agric Food Chem 53, 10166-10178.

20. Tidwell JH \& Allen GL (2001) Fish as food: aquaculture's contribution. EMBO Rep 2, 958-963.

21. Forster J (1999) Aquaculture chickens, salmon: a case study. World Aquac Mag 30, 33-70.

22. Sargent JR, Bell JG, Bell MV, et al. (1995) Requirement criteria for essential fatty acids. J Appl Ichthyol 11, 183-198.

23. Corraze G (1999) Lipid nutrition. In Nutrition and Feeding of Fish and Crustaceans, vol. 1, pp. 111-129 [J Guillaume, S Kaushik, P Bergot and R Metailler, editors]. Chichester, UK: Springer.

24. Tocher DR (2003) Metabolism and functions of lipids and fatty acids in teleost fish. Rev Fish Sci 11, 107-184.

25. Bell JG (2000) Current aspects of lipid nutrition in fish farming. In Biology of Farmed Fish, pp. 114-145 [KD Black and AD Pickering, editors]. Sheffield: Sheffield Academic Press.

26. Sargent JR, Tocher DR \& Bell JG (2002) The lipids. In Fish Nutrition, pp. 181-257 [JE Halver and RW Hardy, editors]. San Diego, CA: Academic Press.

27. Sargent JR, Bell JG, McEvoy J, et al. (1999) Recent developments in the essential fatty acid nutrition of fish. Aquaculture 177, 191-199.
28. Tacon AGJ (1996) Lipid nutritional pathology in farmed fish. Arch Anim Nutr 49, 33-39.

29. Bell JG, McVicar AH, Park MT, et al. (1991) High dietary linoleic acid affects the fatty acid compositions of individual phospholipids from tissues of Atlantic salmon (Salmo salar) - association with stress susceptibility and cardiac lesion. J Nutr 121, 1163-1172.

30. Seierstad SL, Poppe TT, Koppang EO, et al. (2005) Influence of dietary lipid composition on cardiac pathology in farmed Atlantic salmon, Salmo salar L. J Fish Dis 28, 677-690.

31. Carter CG, Bransden MP, Lewis TE, et al. (2003) Potential of thraustochytrids to partially replace fish oil in Atlantic salmon feeds. Mar Biotechnol 5, 480-492.

32. Torstensen BE, Lie O \& Froyland L (2000) Lipid metabolism and tissue composition in Atlantic salmon (Salmo salar L.) - effects of capelin oil, palm oil, and oleic acid-enriched sunflower oil as dietary lipid sources. Lipids 35, 653-664.

33. Bell JG, Henderson RJ, Tocher DR, et al. (2004) Replacement of dietary fish oil with increasing levels of linseed oil: modification of flesh fatty acid compositions in Atlantic salmon (Salmo salar) using a fish oil finishing diet. Lipids 39, 223-232.

34. Bell JG, Tocher DR, Henderson RJ, et al. (2003) Altered fatty acid compositions in Atlantic salmon (Salmo salar) fed diets containing linseed and rapeseed oils can be partially restored by a subsequent fish oil finishing diet. J Nutr 133, 2793-2801.

35. Rosenlund G, Obach A, Sandberg MG, et al. (2001) Effect of alternative lipid sources on long term growth performance and quality of Atlantic salmon (Salmo salar L.). Aquac Res 32, 323-328.

36. Tocher DR, Bell JG, Dick JR, et al. (2000) Polyunsaturated fatty acid metabolism in Atlantic salmon (Salmo salar) undergoing parr-smolt transformation and the effects of dietary linseed and rapeseed oils. Fish Physiol Biochem 23, 59-73.

37. Bell JG, McEvoy J, Tocher DR, et al. (2001) Replacement of fish oil with rapeseed oil in diets of Atlantic salmon (Salmo salar) affects tissue lipid compositions and hepatocyte fatty acid metabolism. J Nutr 131, 1535-1543.

38. Torstensen BE, Froyland L \& Lie O (2004) Replacing dietary fish oil with increasing levels of rapeseed oil and olive oil - effects on Atlantic salmon (Salmo salar L.) tissue and lipoprotein lipid composition and lipogenic enzyme activities. Aquac Nutr 10, 175-192.

39. Ng WK, Sigholt T \& Bell JG (2004) The influence of environmental temperature on the apparent nutrient and fatty acid digestibility in Atlantic salmon (Salmo salar L.) fed finishing diets containing different blends of fish oil, rapeseed oil and palm oil. Aquac Res 35, 1228-1237.

40. Bendiksen EA, Arnesen AM \& Jobling M (2003) Effects of dietary fatty acid profile and fat content on smolting and seawater performance in Atlantic salmon (Salmo salar L.). Aquaculture 225, 149-163.

41. Grisdale-Helland B, Ruyter B, Rosenlund G, et al. (2002) Influence of high contents of dietary soybean oil on growth, feed utilization, tissue fatty acid composition, heart histology and standard oxygen consumption of Atlantic salmon (Salmo salar) raised at two temperatures. Aquaculture 207, 311-329.

42. Polvi SM \& Ackman RG (1992) Atlantic salmon (Salmo salar) muscle lipids and their response to alternative dietary fatty acid sources. J Agric Food Chem 40, 1001-1007.

43. Tocher DR, Bell JG, McGhee F, et al. (2003) Effects of dietary lipid level and vegetable oil on fatty acid metabolism 
in Atlantic salmon (Salmo salar L.) over the whole production cycle. Fish Physiol Biochem 29, 193-209.

44. Beardsell D, Francis J, Ridley D, et al. (2002) Health promoting constituents in plant derived edible oils. $J$ Food Lipids 9, 1-34.

45. Jacobs MN, Covaci A \& Schepens P (2002) Investigation of selected persistent organic pollutants in farmed Atlantic salmon (Salmo salar), salmon aquaculture feed, and fish oil components of the feed. Environ Sci Technol 36, 2797-2805.

46. Bell JG, McGhee F, Dick JR, et al. (2005) Dioxin and dioxin-like polychlorinated biphenyls (PCBS) in Scottish farmed salmon (Salmo salar): effects of replacement of dietary marine fish oil with vegetable oils. Aquaculture 243, 305-314.

47. Pereira MD (2004) Polychlorinated dibenzo-P-dioxins (PCDD), dibenzofurans (PCDF) and polychlorinated biphenyls (PCB): main sources, environmental behaviour and risk to man and biota. Quim Nova 27, 934-943.

48. Bethune C, Seierstad SL, Seljeflot I, et al. (2006) Dietary intake of differently fed salmon: a preliminary study on contaminants. Eur J Clin Invest 36, 193-201.

49. Hamilton MC, Hites RA, Schwager SJ, et al. (2005) Lipid composition and contaminants in farmed and wild salmon. Environ Sci Technol 39, 8622-8629.

50. Berntssen MHG, Giskegjerde TA, Rosenlund G, et al. (2007) Predicting World Health Organization toxic equivalency factor dioxin and dioxin-like polychlorinated biphenyl levels in farmed Atlantic salmon (Salmo salar) based on known levels in feed. Environ Toxicol Chem 26, 13-23.

51. Schwarz M \& Appel KE (2005) Carcinogenic risks of dioxin: mechanistic considerations. Regul Toxicol Pharmacol 43, 19-34.

52. Mozaffarian D \& Rimm EB (2006) Fish intake, contaminants, and human health - evaluating the risks and the benefits. JAMA 296, 1885-1899.

53. Schrock ME, Armbruster MJ, Riggs KB, et al. (1996) Simultaneous determination of PCDD/PCDF and dioxinlike PCBs in edible vegetable oils. Organohal Comp 27, 386-390.

54. Gatlin DM, Barrows FT, Brown P, et al. (2007) Expanding the utilization of sustainable plant products in aquafeeds: a review. Aquac Res 38, 551-579.

55. Ruxton CHS, Reed SC, Simpson MJA, et al. (2007) The health benefits of omega- 3 polyunsaturated fatty acids: a review of the evidence. J Hum Nutr Diet 20, 275-285.

56. Tapiero H, Ba GN, Couvreur P, et al. (2002) Polyunsaturated fatty acids (PUFA) and eicosanoids in human health and pathologies. Biomed Pharmacother 56, 215-222.

57. Simopoulos AP (2002) Omega-3 fatty acids in inflammation and autoimmune diseases. J Am Coll Nutr 21, 495-505.

58. Kris-Etherton PM, Hecker KD \& Binkoski AE (2004) Polyunsaturated fatty acids and cardiovascular health. Nutr Rev 62, 414-426.

59. Horrocks LA \& Yeo YK (1999) Health benefits of docosahexaenoic acid (DHA). Pharm Res 40, 211-225.

60. Takahata K, Monobe K, Tada M, et al. (1998) The benefits and risks of $n-3$ polyunsaturated fatty acids. Biosci Biotechnol Biochem 62, 2079-2085.

61. Brouwer IA, Geelen A \& Katan MB (2006) n-3 Fatty acids, cardiac arrhythmia and fatal coronary heart disease. Prog Lipid Res 45, 357-367.

62. Shahidi F \& Miraliakbari H (2004) Omega-3 (n-3) fatty acids in health and disease: Part I - cardiovascular disease and cancer. J Med Food 7, 387-401.
63. MacLean CH, Newberry SJ, Mojica WA, et al. (2006) Effects of omega-3 fatty acids on cancer risk - a systematic review. JAMA 295, 403-415.

64. Ruxton CHS, Calder PC, Reed SC, et al. (2005) The impact of long-chain $n-3$ polyunsaturated fatty acids on human health. Nutr Res Rev 18, 113-129.

65. Simopoulos AP (2002) The importance of the ratio of omega-6/omega-3 essential fatty acids. Biomed Pharmacother 56, 365-379.

66. Goodstine SL, Zheng TZ, Holford TR, et al. (2003) Dietary $(n-3) /(n-6)$ fatty acid ratio: possible relationship to premenopausal but not postmenopausal breast cancer risk in US women. J Nutr 133, 1409-1414.

67. Gibson RA, Makrides M, Neumann MA, et al. (1994) Ratios of linoleic acid to $\alpha$-linolenic acid in formulas for term infants. J Pediatr 125, S48-S55.

68. Meyer BJ, Mann NJ, Lewis JL, et al. (2003) Dietary intakes and food sources of omega- 6 and omega- 3 polyunsaturated fatty acids. Lipids 38, 391-398.

69. Zheng XZ, Torstensen BE, Tocher DR, et al. (2005) Environmental and dietary influences on highly unsaturated fatty acid biosynthesis and expression of fatty acyl desaturase and elongase genes in liver of Atlantic salmon (Salmo salar). Biochim Biophys Acta 1734, 13-24.

70. Turchini GM, Francis DS \& de Silva SS (2006) Fatty acid metabolism in the freshwater fish Murray cod (Maccullochella peelii peelii) deduced by the whole-body fatty acid balance method. Comp Biochem Physiol B 144, 110-118.

71. Francis DS, Turchini GM, Jones PL, et al. (2007) Dietary lipid source modulates in vivo fatty acid metabolism in the freshwater fish, Murray cod (Maccullochella peelii peelii). $J$ Agric Food Chem 55, 1582-1591.

72. Henderson RJ \& Tocher DR (1987) The lipid composition and biochemistry of freshwater fish. Prog Lipid Res 26 , 281-347.

73. Bell JG, Sargent JR \& Raynard RS (1992) Effects of increasing dietary linoleic acid on phospholipid fatty acid composition and eicosanoid production in leukocytes and gill cells of Atlantic salmon (Salmo salar). Prostaglandins Leukot Essent Fatty Acids 45, 197-206.

74. Bell JG, Tocher DR, Farndale BM, et al. (1997) The effect of dietary lipid on polyunsaturated fatty acid metabolism in Atlantic salmon (Salmo salar) undergoing parr-smolt transformation. Lipids 32, 515-525.

75. Tocher DR, Bell JG, Dick JR, et al. (2003) Effects of dietary vegetable oil on Atlantic salmon hepatocyte fatty acid desaturation and liver fatty acid compositions. Lipids 38, 723-732.

76. Tocher DR, Bell JG, Dick JR, et al. (1997) Fatty acyl desaturation in isolated hepatocytes from Atlantic salmon (Salmo salar): stimulation by dietary borage oil containing $\gamma$-linolenic acid. Lipids 32, 1237-1247.

77. Tocher DR, Bell JG, MacGlaughlin P, et al. (2001) Hepatocyte fatty acid desaturation and polyunsaturated fatty acid composition of liver in salmonids: effects of dietary vegetable oil. Comp Biochem Physiol B 130, 257-270.

78. Tocher DR, Fonseca-Madrigal J, Bell JG, et al. (2002) Effects of diets containing linseed oil on fatty acid desaturation and oxidation in hepatocytes and intestinal enterocytes in Atlantic salmon (Salmo salar). Fish Physiol Biochem 26, 157-170.

79. Zheng XZ, Tocher DR, Dickson CA, et al. (2004) Effects of diets containing vegetable oil on expression of genes involved in highly unsaturated fatty acid biosynthesis in liver of Atlantic salmon (Salmo salar). Aquaculture 236, 467-483. 
80. Zheng XZ, Tocher DR, Dickson CA, et al. (2005) Highly unsaturated fatty acid synthesis in vertebrates: new insights with the cloning and characterization of a Delta 6 desaturase of Atlantic salmon. Lipids 40, 13-24.

81. Miller MR, Nichols PD \& Carter CG (2007) Replacement of dietary fish oil for Atlantic salmon parr (Salmo salar L.) with a stearidonic acid containing oil has no effect on omega-3 long-chain polyunsaturated fatty acid concentrations. Comp Biochem Physiol B 146, 197-206.

82. Ghioni C, Porter AEA, Taylor GW, et al. (2002) Metabolism of $18: 4 n-3$ (stearidonic acid) and $20: 4 n-3$ in salmonid cells in culture and inhibition of the production of prostaglandin F-2 $\alpha(\mathrm{PGF}(2 \alpha))$ from $20: 4 n-6$ (arachidonic acid). Fish Physiol Biochem 27, 81-96.

83. Reijnders L \& Huijbregts MAJ (2008) Palm oil and the emission of carbon-based greenhouse gases. J Clean Prod 16, 477-482.

84. Organisation for Economic Co-operation and Development \& Food and Agriculture Organization of the United Nations (2007) OECD-FAO Agricultural Outlook 2007-2016. http://www.oecd.org/dataoecd/6/10/38893266.pdf

85. Ostlund RE (2002) Phytosterols in human nutrition. Annu Rev Nutr 22, 533-549.

86. Trautwein EA, Duchateau G, Lin YG, et al. (2003) Proposed mechanisms of cholesterol-lowering action of plant sterols. Eur J Lipid Sci Tech 105, 171-185.

87. Earnest CP, Mikus CR, Lemieux I, et al. (2007) Examination of encapsulated phytosterol ester supplementation on lipid indices associated with cardiovascular disease. Nutrition 23, 625-633.

88. Kuhlmann K, Lindtner O, Bauch A, et al. (2005) Simulation of prospective phytosterol intake in Germany by novel functional foods. Br J Nutr 93, 377-385.

89. Law M (2000) Plant sterol and stanol margarines and health. Br J Nutr 320, 861-864.

90. Engel R \& Schubert H (2005) Formulation of phytosterols in emulsions for increased dose response in functional foods. Inn Food Sci Emerg Technol 6, 233-237.

91. Miller MR, Nichols PD \& Carter CG (2008) The digestibility and accumulation of dietary phytosterols in Atlantic salmon (Salmo salar $\mathrm{L}$ ) fed diets with replacement plant oils. Lipids 43, 549-557.

92. Kew S, Wells S, Thies F, et al. (2003) The effect of eicosapentaenoic acid on rat lymphocyte proliferation depends upon its position in dietary triacylglycerols. $J$ Nutr 133, 4230-4238.

93. Kew S, Gibbons ES, Thies F, et al. (2003) The effect of feeding structured triacylglycerols enriched in eicosapentaenoic or docosahexaenoic acids on murine splenocyte fatty acid composition and leucocyte phagocytosis. $\mathrm{Br} \mathrm{J}$ Nutr 90, 1071-1080.

94. Lucas A, Quinlan P, Abrams S, et al. (1997) Randomised controlled trial of a synthetic triglyceride milk formula for preterm infants. Arch Dis Child 77, F178-F184.

95. Bell MV, Henderson RJ \& Sargent JR (1986) The role of polyunsaturated fatty acids in fish. Comp Biochem Physiol B 83, 711-719.

96. Miller MR (2007) The Assessment of Omega 3 Oil Sources for Use in Aquaculture - Alternatives to the Unsustainable Harvest of Wild Fish Stocks. Hobart: University of Tasmania.

97. Miller MR, Nichols PD, Barnes J, et al. (2006) Regiospecificity profiles of storage and membrane lipids from the gill and muscle tissue of Atlantic salmon (Salmo salar L.) grown at elevated temperature. Lipids 41, 865-876.
98. Hazel JR, McKinley SJ \& Williams EE (1992) Thermal adaptation in biological membranes - interacting effects of temperature and $\mathrm{pH}$. Comp Biochem Physiol B 162, 593-601.

99. Hazel JR (1984) Effects of temperature on the structure and metabolism of cell membranes. Am J Physiol 246, 460-470.

100. Hazel JR, Williams EE, Livermore R, et al. (1991) Thermal adaptation in biological membranes - functional significance of changes in phospholipid molecular species composition. Lipids 26, 277-282.

101. Zwingelstein G, Malak NA \& Brichon G (1978) Effect of environmental temperature on the biosynthesis of liver phosphatidylcholine in the trout (Salmo garirdneri). $J$ Therm Biol 3, 229-233.

102. Miller NGA, Hill MW \& Smith MW (1976) Positional and species analysis of membrane phospholipids extracted from goldfish adapted to different environmental temperatures. Biochim Biophys Acta 455, 644-654.

103. Hazel JR (1979) The influence of thermal acclimation on membrane lipid composition of rainbow trout liver. Am J Physiol 236, 91-101.

104. Hazel JR \& Landrey SR (1988) Time course of thermal adaptation in plasma membranes of trout kidney. 1 . Headgroup composition. Am J Physiol 255, R622-R627.

105. Farkas T, Dey I, Buda C, et al. (1994) Role of phospholipid molecular species in maintaining lipid membrane structure in response to temperature. Biophys Chem 50, 147-155.

106. Tocher DR \& Sargent JR (1990) Effect of temperature on the incorporation into phospholipid classes and metabolism via desaturation and elongation of $n-3$ and $n-6$ polyunsaturated fatty acids in fish cells in culture. Lipids 25, $435-442$.

107. Ruyter B, Rosjo C, Grisdale-Helland B, et al. (2003) Influence of temperature and high dietary linoleic acid content on esterification, elongation, and desaturation of PUFA in Atlantic salmon hepatocytes. Lipids 38, 833-840.

108. Bendiksen EA \& Jobling M (2003) Effects of temperature and feed composition on essential fatty acid ( $\omega 3$ and $\omega 6)$ retention in Atlantic salmon (Salmo salar L.) parr. Fish Physiol Biochem 29, 133-140.

109. Jobling M \& Bendiksen EA (2003) Dietary lipids and temperature interact to influence tissue fatty acid compositions of Atlantic salmon, Salmo salar L., parr. Aquac Res 34, 1423-1441.

110. Olsen RE \& Ringo E (1998) The influence of temperature on the apparent nutrient and fatty acid digestibility of Arctic charr, Salvelinus alpinus L. Aquac Res 29, 695-701.

111. Bendiksen EA, Berg OK, Jobling M, et al. (2003) Digestibility, growth and nutrient utilisation of Atlantic salmon parr (Salmo salar L.) in relation to temperature, feed fat content and oil source. Aquaculture 224, 283-299.

112. Bendiksen EA, Jobling M \& Arnesen AM (2002) Feed intake of Atlantic salmon parr Salmo salar L. in relation to temperature and feed composition. Aquac Res 33, 525-532.

113. Oidtmann B, Baier M \& Hoffmann R (2003) Detection of prion protein in fish - how likely are transmissible spongiform encephalopathies in fish? Arch Lebensmittelhyg 54, $141-145$.

114. Watkins C (2007) Is krill fishing sustainable? Inform 18, 591.

115. Watkins C (2007) Krill oil: next generation source of omega-3s? Inform 18, 588-590.

116. Kawaguchi S \& Nicol S (2007) Learning about Antarctic krill from the fishery. Antarc Sci 19, 219-230.

117. Virtue P, Johannes RE, Nichols PD, et al. (1995) Biochemical composition of Nyctiphanes australis and its 
possible use as an aquaculture feed source - lipids, pigments and fluoride content. Mar Biol 122, 121-128.

118. Phleger CF, Nelson MM, Mooney BD, et al. (2002) Interannual and between species comparison of the lipids, fatty acids and sterols of Antarctic krill from the US AMLR Elephant Island survey area. Comp Biochem Physiol B 131, 733-747.

119. Virtue P, Nichols PD, Nicol S, et al. (1996) Reproductive trade off in male Antarctic krill, Euphausia superba. Mar Biol 126, 521-527.

120. Hill SL, Murphy EJ, Reid K, et al. (2006) Modelling Southern Ocean ecosystems: krill, the food-web, and the impacts of harvesting. Biol Rev Camb Philos Soc 81, $581-608$.

121. Lee C-S, P'Bryen PJ \& Marcus NH (2005) Copepods in Aquaculture. Oxford, UK: Blackwell Publishing.

122. Drillet G, Jorgensen NOG, Sorensen TF, et al. (2006) Biochemical and technical observations supporting the use of copepods as live feed organisms in marine larviculture. Aquac Res 37, 756-772.

123. McKinnon AD, Duggan S, Nichols PD, et al. (2003) The potential of tropical paracalanid copepods as live feeds in aquaculture. Aquaculture 223, 89-106.

124. Brenner RR (1981) Nutritional and hormonal factors influencing desaturation of essential fatty acids. Prog Lipid Res 20, 41-47.

125. Rowe DK, Thorpe JE \& Shanks AM (1991) Role of fat stores in the maturation of male Atlantic salmon (Salmo salar) parr. Can J Fish Aquat Sci 48, 405-413.

126. Bell JG \& Sargent JR (2003) Arachidonic acid in aquaculture feeds: current status and future opportunities. Aquaculture 218, 491-499.

127. Miller MR, Bridle AR, Nichols PD, et al. (2008). Increased elongase and desaturase gene expression with stearidonic acid enriched diet did not enhance long-chain omega 3 content of seawater Atlantic salmon (Salmo salar L.). J Nutr, 138 (In the Press).

128. Bell JG, Strachan F, Good JE, et al. (2006) Effect of dietary Echium oil on growth, fatty acid composition and metabolism, gill prostaglandin production and macrophage activity in Atlantic cod (Gadus morhua L.). Aquac Res 37, 606-617.

129. Tocher DR, Dick JR, MacGlaughlin P, et al. (2006) Effect of diets enriched in delta 6 desaturated fatty acids (18:3n-6 and $18: 4 n-3$ ), on growth, fatty acid composition and highly unsaturated fatty acid synthesis in two populations of Arctic charr (Salvelinus alpinus L.). Comp Biochem Physiol B 144, 245-253.

130. Gjedrem T (2000) Genetic improvement of cold water fish species. Aquac Res 31, 25-33.

131. Lewis TE, Nichols PD \& McMeekin TA (1999) The biotechnological potential of thraustochytrids. Mar Biotechnol 1, 580-587.

132. Cavalier-Smith T, Allsopp M \& Chao EE (1994) Thraustochytrids are chromists, not fungi - 18s rRNA signatures of heterokonta. Philos Trans Roy Soc Lond B 346, 387-397.

133. Barclay W \& Zeller S (1996) Nutritional enhancement of $n-3$ and $n-6$ fatty acid in rotifers and Artemia nauplii by feeding spray-dried Schizochytrium sp. J World Aquac Soc 27, 314-322.

134. Nichols DS, Hart P, Nichols PD, et al. (1996) Enrichment of the rotifer Brachionus plicatilis fed an Antarctic bacterium containing polyunsaturated fatty acids. Aquaculture 147, $115-125$.

135. Lewis T, Nichols PD, Hart PR, et al. (1998) Enrichment of rotifers Brachionus plicatilis with eicosapentaenoic acid and docosahexaenoic acid produced by bacteria. $J$ World Aquac Soc 29, 313-318.

136. Miller MR, Nichols PD \& Carter CG (2007) Replacement of fish oil with thraustochytrid Schizochytrium sp. L. oil in Atlantic salmon parr (Salmo salar L) diets. Comp Biochem Physiol A 148, 382-392.

137. Nichols PD, Blackburn SI \& Green AG (2004) Omega-3 oils down under - an update. Inform 15, 383-385.

138. Browdy C, Seaborn G, Atwood H, et al. (2006) Comparison of pond production efficiency, fatty acid profiles, and contaminants in Litopenaeus vannamei fed organic plantbased and fish-meal-based diets. J World Aquac Soc 37, 437-451.

139. Robert SS, Singh SP, Zhou XR, et al. (2005) Metabolic engineering of Arabidopsis to produce nutritionally important DHA in seed oil. Funct Plant Biol 32, 473-479.

140. Robert SS (2006) Production of eicosapentaenoic and docosahexaenoic acid-containing oils in transgenic land plants for human and aquaculture nutrition. Mar Biotechnol 8, 103-109.

141. Sayanova OV \& Napier JA (2004) Eicosapentaenoic acid: biosynthetic routes and the potential for synthesis in transgenic plants. Phytochem 65, 147-158.

142. Abbadi A, Domergue F, Meyer A, et al. (2001) Transgenic oilseeds as sustainable source of nutritionally relevant $\mathrm{C} 20$ and C22 polyunsaturated fatty acids? Eur J Lipid Sci Tech 103, 106-113.

143. Sayanova O, Davies GM, Smith MA, et al. (1999) Accumulation of delta(6)-unsaturated fatty acids in transgenic tobacco plants expressing a delta(6)-desaturase from Borago officinalis. J Exp Bot 50, 1647-1652.

144. Sayanova O, Smith MA, Lapinskas P, et al. (1997) Expression of a borage desaturase cDNA containing an $\mathrm{N}$-terminal cytochrome $\mathrm{b}(5)$ domain results in the accumulation of high levels of delta(6)-desaturated fatty acids in transgenic tobacco. Proc Natl Acad Sci U S A 94 4211-4216.

145. Qi BX, Fraser T, Mugford S, et al. (2004) Production of very long chain polyunsaturated omega-3 and omega-6 fatty acids in plants. Nat Biotechnol 22, 739-745.

146. Damude HG \& Kinney AJ (2007) Engineering oilseed plants for sustainable, land-based source of long chain polyunsaturated fatty acids. Lipids 42, 179-185.

147. Cox DN, Evans G \& Lease HJ (2008) Australian consumers' preferences for conventional and novel sources of long chain omega-3 fatty acids: a conjoint study. Food Qual Pref 19, 306-314.

148. Cox DN, Evans G \& Lease HJ (2008) Predictors of Australian consumers' intentions to consume conventional and novel sources of long chain omega- 3 fatty acids. Public Health Nutr 11, 8-16. 